3. Roenne, G. (1944).-Local Treatment of Intrabulbar Infections. 2. The Clinical and Histological Picture of the Staphylococcus Infection. Acta Ophthal., Vol. XXII, p. 105.

4. (1944). - Animal and Clinical Experiments with Penicillin Treatment of Intrabulbar Infections. Trans. Ophthal. Soc. Copenhagen, 247th meeting. March 23, 1944. Nordisk Medicin, Vol. XXVI, p. 1230 (Danish).

5. - (1944).-Local Treatment of Intrabulbar Infections. 3. Determination of Virulence with the Rabbit Eye as Test-object. Acta Path. et Microbiol. Scand. Suppl., Vol LIV, p. 241.

6. (1944). - Local Treatment of Intrabulbar Infections. 4. The Growth Phases of Staphylococcus, especially the Generation Period, examined with the Rabbit Eye as a Test-object. Acta Path. et Microbiol. Scand. Suppl., Vol. LIV, p. 247.

7. _ (1944).-Further Experiments with Penicillin Treatment of Intra-ocular Infections. Trans. Ophthal. Soc. Copenhagen, 250th meeting, December 11, 1944 (Danish).

8. - (1945). - Local Treatment of Intrabulbar Infections. 5. Treatment of the Staphylococcus Panophthalmia with Intravitreal Injection of Chloramine-T. Acta Ophthal., Vol. XXIII, p. 367.

1. von SallmanN, L. (1943) - Penicillin and Sulfadiazine in the Treatment of Experimental Intra-ocular Infection with Pneumococcus. Arch. Ophthal., Vol. XXX, p. 426.

2. - (1944).-Penicillin and Sulfadiazine in the Treatment of Experimental Intra-ocular Infection with staphylococcus aureus and clostridiumW elchii. Arch. Ophthal., Vol. XXXI, p. 54.

von SallmanN, L., MEYer, K. and DI GRANDI, J. (1944).-Experimental Study on Penicillin Treatment of Ectogenous Infection of Vitreous. Arch. Ophthal., Vol. XXXII, p. 179.

STRUBLE, G. E. and Bel.lows, J. G. (1944).-Studies on the Distribution of of Penicillin in the Eye. Ji. Amer. Med. Assoc., Vol. CXXV, p. 685.

\title{
RETINAL DETACHMENT DUE TO WAR TRAUMA
}

BY

\section{H. B. Stallatad}

LONDON

THIs enquiry was made to find out the incidence of retinal detachment directly attributable to the effects of war missiles, the relation of this incidence to other types of retinal detachment occurring in soldiers serving in a field force, and the comparative results of treatment and prognosis.

In the 1914-18 war Gonin's principle of locating a retinal tear or tears accurately and sealing these by diathermy with subsequent drainage of the inter-retinal fluid was not known or practised and so in the 1939-45 war an opportunity arose to try out modern surgical treatment in such cases as seemed to offer a reasonable chance of effecting some improvement.

This work was done in the M.E.F. $1941-43$ and the B.L.A. 1944-45 where to the 15th (Scottish) General Hospital in Egypt, the 102nd Field Hospital in Normandy and the 108th General Hospital in Belgium the majority of retinal detachment cases and serious ocular and orbital wounds with retained foreign bodies were referred. 
In the M.E.F. 78 cases of retinal detachment were treated and in the B.L.A. 18, making a total of 96 . I have classified these cases as follows :-

TABLE A

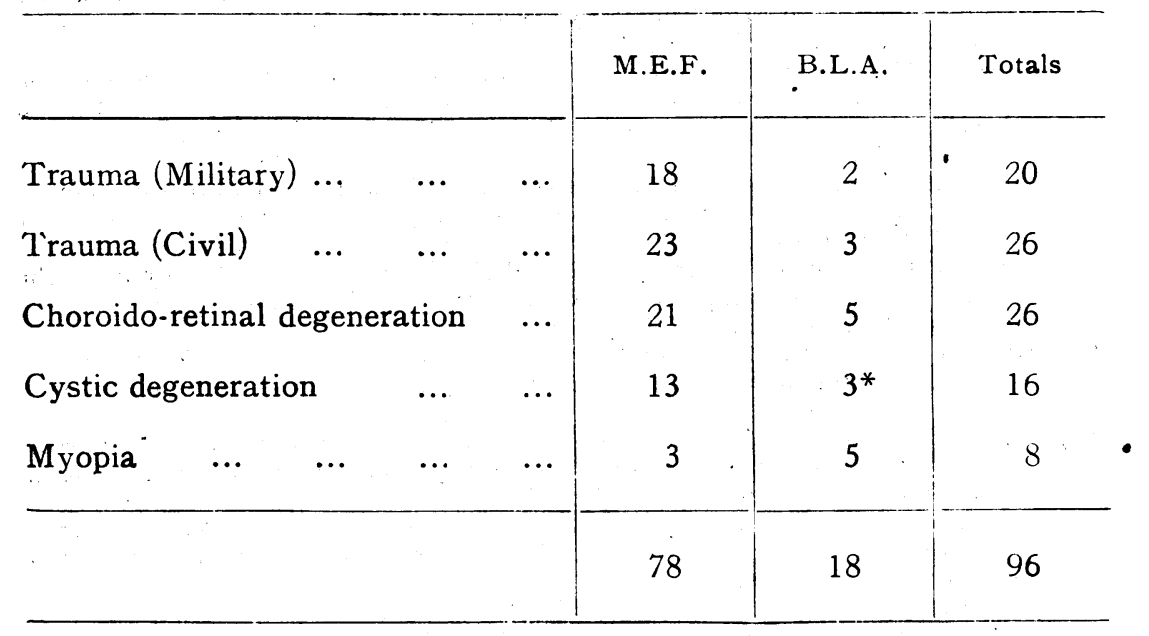

* One of these had both eyes operated on

(Included in the classification cystic degeneration were 12 cases in which part of the detachment appeared cystic. In 9 of these around the base of the cyst there was a well defined arc of pigmentary degeneration in the choroid and retina at the posterior periphery of the cyst up to the ora serrata where these changes ceased. In 3 others these changes were faint. The ophthalmoscopic appearance suggested a line of adhesion between the retina and choroid which was more marked in some cases than in others. In one case these changes were present in only part of the arc at the posterior periphery of the cyst. A retinal tear or tears were found in all 12 cases and 7 of these showed multiple tears. In 2 cases a sudden spread of the detachment from the limits of the cystic area caused separation of the macula).

It will be seen from Table A. that approximately 20 per cent. of all types of retinal detachment occurring in a field force were due to trauma from military missiles.

The incidence of retinal detachment due to military trauma among other battle casualties is impossible to assess with arcuracy for in the M.E.F. the wounded were distributed to at least 9 General Hospitals with eye surgeons and in some instances went through as many as 4 of these. There was therefore in the early days of the Western desert campaign a multiplication of statistics which was confusing enough, and this was increased by security measures 
which made it impossible for Medical H.Q. to disclose information about the numbers of wounded. There were 475 battle casualties admitted to the eye department of the 15th (Scottish) General Hospital beginning with General Cunningham's offensive in 1941 and ending with the conquest of North Africa in May, 1943. Of these 18 had retinal detachment due to military trauma. But this figure is misleading for many of the cases sent to this hospital were selected.

In the B.L.A. precision in this matter was also rendered impossible by the rapid evacuation of wounded by sea and air in the early stages of the Normandy campaign and indeed until early September, 1944, we were seldom allowed to retain any but a few special cases for more than 2 or 3 days. There were only 2 cases of retinal detachment due to military trauma.

So all that may be said is an impression that retinal detachment due to war missiles in which the eye is left reasonably intact and has not a large penetrating wound nor is collapsed or so grossly disorganized as to make excision necessary is a rarity in the wounded.

Of all types of retinal detachments classified above 13 were officers-one of these a nursing officer Q.A.I.M.N.S.(R.); 16 were British other ranks, Royal Navy 2 cases, Royal Air Force 2 cases, Royal Canadian Air Force 1 case, Royal Canadian Engineers 1, Canadian Infantry 1 and Merchant Navy 1 case.

The nationalities were British 76. Canadian 3, New Zealand 1. South African 3, Indian 3, Greek 4, Polish 2, Czech 1, Yugo-Slav 1 , German 1 and Italian 1

Table B. shows the age incidence of the various types of detachment.

TABLE B

\begin{tabular}{c|c|c|c|c|c}
\hline $\begin{array}{c}\text { Age } \\
\text { (years) }\end{array}$ & $\begin{array}{c}\text { Trauma } \\
\text { Military }\end{array}$ & $\begin{array}{c}\text { Trauma } \\
\text { Civil }\end{array}$ & $\begin{array}{c}\text { Choroido-retinal } \\
\text { degeneration }\end{array}$ & $\begin{array}{c}\text { Cystic } \\
\text { degeneration }\end{array}$ & Myopia \\
\hline $20-30$ & 16 & 21 & 21 & 10 & 3 \\
$31-40$ & 4 & 5 & 3 & 5 & 2 \\
$41-47$ & - & - & 2 & 1 & 1 \\
\hline & 20 & 26 & 26 & 16 & 6 \\
\hline
\end{tabular}

As might be expected the highest incidence of retinal detachment, particularly that due to military trauma and the types of 
trauma seen in civil practice is in young soldiers in the third decade of life for these form the majority of a field force.

\section{Analysis of cases of military trauma. Twenty cases}

The area of retinal detachment was extensive in a number of these cases. Large splashes of blood on the retina, in the choroid and vitreous, exudates, subsequent fibrous organization of intra-ocular blood, the presence of blood between the retina and the choroid, and the lowered intra-ocular pressure as the result of severe concussion of the eye from blast were factors against successful treatment. It is probable that vitreous gel passes through some of the large ragged rents in the retina and is a mechanical factor in preventing choroido-retinal adhesions from forming after diathermy.

In one case in this series of 20 the intra-ocular changes were such that surgical operation seemed to hold out no hope of effecting any improvement. The soldier had sustained a blast injury from an aerial bumb which exploded 200 yards to his right front. Three months after the injury the retina was totally detached; dense white broad sheets of organized blood clot were adherent to it in the lower half of the eye, over the macula, in the upper nasal quadrant, and in front of the equator above. The inferior branches of the central retinal vessels immediately below the optic disc were kinked and tortuous. There was much pigmentary disturbance in the retina, and the intra-ocular pressure was $6.5 \mathrm{~mm} . \mathrm{Hg}$. Vitreous had herniated forwards into a coloboma of the iris in the lower temporal quadrant, the suspensory ligament having been ruptured at this site.

Spontaneous recovery occurred in 2 officers. One of these, Lieut. C. McL. S., aged 23 years, a Royal Engineer, was affected in his right eye by the blașt of a land-mine explosion on October 20, 1944, in Belgium. Three quadrants of the retina were detached, only the upper nasal quadrant remained in place and a corresponding part of the lower temporal field was present. In the upper temporal quadrant the retina was ballooned forwards and the macula was detached. There was a faint "sunflower" opacity in the posterior lens cortex. The patient was wearing - 5.5 D.sph. The right and injured eye was further complicated by the effects of an old injury. In April, 1943, an explosion of gun-cotton had blown a foreign body into this eye. This foreign body was oval in shape, about $1.5 \mathrm{~mm}$. long, lay in the 6 o'clock meridian near to the ora serrata. The end near the ora serrata was free and that nearer the equator attached to the retina by a fibrous strand, and on this anchorage it floated in the vitreous and changed position on postural alterations of the eye and head. This foreign body was non-magnetic. The wound of entry was not evident. A scarred area of retina and choroid below the macula and near the 
equator, from which greyish and white tags of fibrous tissue projected into the vitreous, suggested that the foreign body may have struck the fundus at this site and rebounded into the vitreous. Some vitreous opacities, a few of which were coarse, lay in front of the equator in the lower temporal quadrant. Some red blood cells could be seen with the slit-lamp in the anterior part of the vitreous. Repeated examinations in different postures revealed no hole or split in the retina at any time. At first I thought that the fibrous bands passing from the retina into the vitreous and the presence of the intra-ocular foreign body might operate against successful reposition of the retina.

The patient was confined to bed, lying on 2 pillows, the right eye was atropinized and both eyes occluded by pads and a binocular bandage. On the seventh day after the injury the retina in the upper temporal quadrant was in place. His position was then changed to sitting and during the next 14 days the retina was replaced over the macular area and then to the equator and slightly beyond in the lower quadrants of the eye. Twenty-two days after the injury a shallow residual detachment remained near the ora serrata around the site of the intra-ocular foreign body between the 5 and 7 o'clock meridian. He was then allowed to wear stenopaic glasses. For some 10 more days there was little change in this area of detachment then within 7 days the inter-retinal fluid absorbed and on November 28, 1944, 39 days after injury the retina became replaced and the visual field fully restored and right vision $6 / 18$. On December 6,1944 , vision was $6 / 12$ with glasses correcting the myopia ( -5.5 D.sph.). Later this became $6 / 6$ despite the early posterior cortical lens changes, the probable sequelae of the 1943 injury. Follow-up examinations up to June 21, 1945, when this officer was last seen in Belgium, showed the retina completely in place, the visual field full and the visual acuity maintained at 6/6 with - 5.5 D.sph.

This case affords several useful lessons. (1) That in blast injuries where there is no tear or split expectant treatment is justifiable. (2) That the visual results after reposition of detachment of the macula are good where there is no retinal tear. no pathological lesion at the macula and there has been no operative treatment and the eye has been treated expectantly.

Spontaneous recovery also occurred in another officer, Major A. D., aged 29 years, who was wounded by a fragment of shell which struck the temporal end of his left supra-orbital margin whilst he was reconnoitring the position of some German tanks on an escarpment in the Western desert. His head was exposed above the tank turret. There were a severe contusion of the left eye and a rupture of the choroid at the macula, and large splashes of blood and exudate were present on the retina and in the choroid 
and vitreous of the upper temporal quadrant. One month after this wound the retina in the upper temporal quadrant became detached. There was no hole evident. The intra-ocular pressure was $6 \mathrm{~mm} . \mathrm{Hg}$ and visual acuity less than $6 / 60$. Postural treatment was tried for three and a half weeks. The detached area became slightly smaller and some of the inter-retinal fluid was absorbed. Within two months of the onset of the detachment the retina was completely restored to its normal place.

In this group of 20 cases 3 had lost one eye (the left in each case) which was destroyed beyond hope of repair at the time of wounding. In 9 cases the right was affected, and in the 11th the retina was detached in the left eye. In most the actual duration of the retinal detachment was difficult to assess accurately. In some instances it was apparent a few days after wounding; in others it was obscured by intra-ocular haemorrhage and did not become evident for several weeks, while in a few it occurred as a late sequel, 6 to 14 months after the injury. In the latter the contracture of fibrous tissue attached to the retina and the lowered intra-ocular pressure were. likely causes. The times, taken from the date of wounding, were : 1 to 11 days, 7 cases; 1 to 4 months, 9 cases; 4 to 6 months, 3 cases; and 14 months, 1 case.

Retinal detachment occurred in association with an intra-ocular foreign body in 5 cases. The detachment happened immediately in one case, 53 days later in another, and in a third 6 weeks after the extraction of an intra-ocular foreign body, at another hospital, by the posterior route, in which diathermy was not used at the site of the sclerotomy. In the other 2 cases the date of onset of the retinal detachment was not known. Of the intra-ocular foreign bodies, three were extracted by the magnet through the posterior (scleral) route, one was removed by a snare and forceps guided under ophthalmoscopic view, and another was too small and non. magnetic, and so was left.

In 3 cases tangential cuts in the sclera were caused by a shell fragment, which did not remain in the eye but passed on into the orbital tissues. Blast from a shell. a mortar bomb and an aerial bomb caused retinal detachment in 4 cases; hand grenades were responsible for 5 , land-mines for 2 , a rifle-butt for 1 , a bullet traversing the orbit for 1 , and a fragment of mortar bomb for 1 .

The site of the retinal detachment was total in 2 cases, almost total in 2. involved the lower half of the retina in 5, the upper and lower temporal quadrants in 2 , the upper and lower temporal quadrants and lower nasal quadrant in 5, the upper and lower nasal quadrants and the lower temporal quadrant in 2 , the upper temporal quadrant in 1 , and a curtain-like detachment affecting the upper nasal and upper temporal quadrants and the lower nasal and lower temporal quadrants in 1 (see Fig. 1).* There was no

"The blocks for Figs. 1, 2, and 3 have been lent by the Editor of the Brit. Med. $J l$. to whom my best thanks are due. 
hole present in this case. Fig. 2 is a diagram of the operation. The internal rectus muscle was divided temporarily at its insertion in front of two mattress sutures. Beneath the muscle belly was seen a tangential wound in the sclera just in front of the equator in the

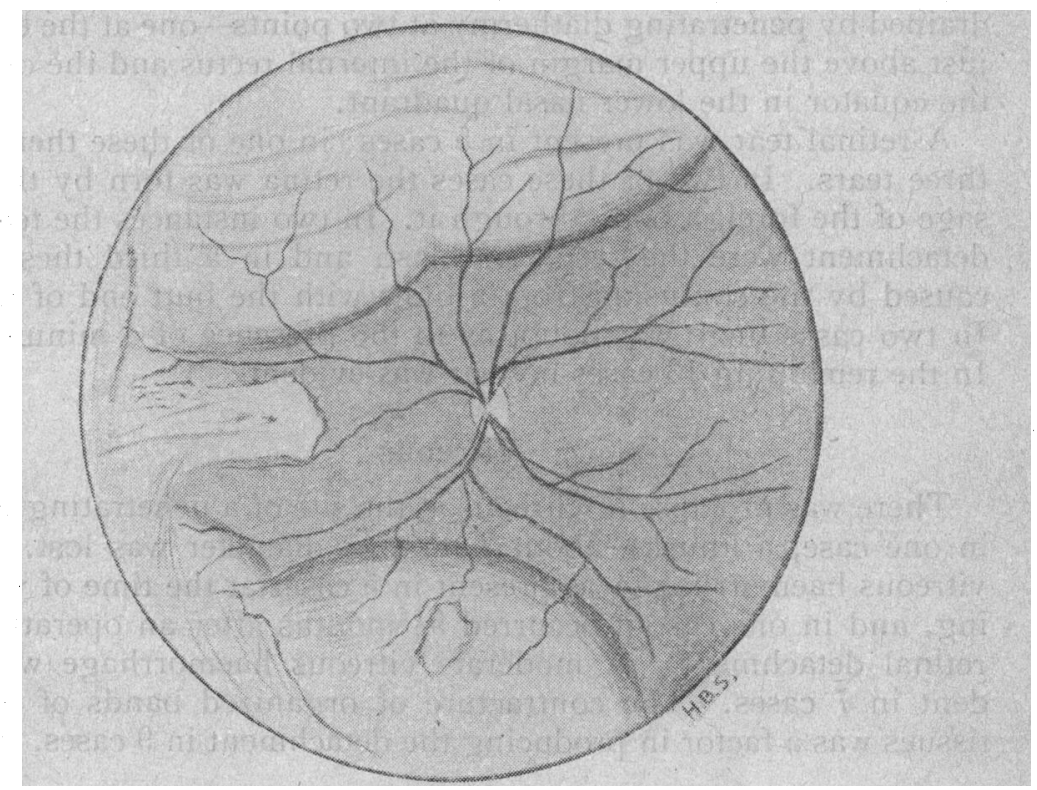

FIG. 1.

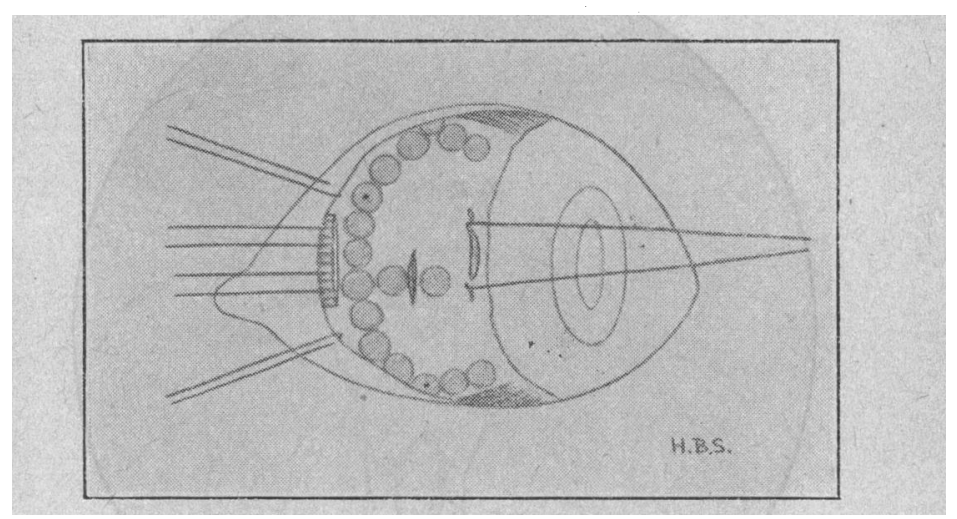

Fig. 2.

9 o'clock meridian. The wound was linear, $3 \mathrm{~mm}$. long, vertical and gaping; it revealed the choroid. The application of surface diathermy on either side of it closed it by contracting the sclera. A line of surface diathermy application was made at the equator 
between the nasal borders of the superior and inferior rectus muscles. From the upper and lower ends of this line applications of diathermy were made forwards to the ora serrata. Thus a frame was made just clear of the scar tissue inside the eye and with the object of pinning down the retina. The inter-retinal fluid was drained by penetrating diathermy at two points-one at the equator just above the upper margin of the internal rectus and the other at the equator in the lower nasal quadrant.

A retinal tear was present in 5 cases; in one of these there were three tears. In two of these cases the retina was torn by the passage of the foreign body through it. In two instances the tear and detachment were the result of blast, and in a third these were caused by the contusion from a blow with the butt end of a rifle: In two cases there was doubt as to the presence of a minute tear. In the remaining 13 cases no tear was evident.

\section{Vitreous}

There was prolapse of vitreous at the site of a penetrating wound in one case, a knuckle about $3 \mathrm{~mm}$. in diameter was lost. Some vitreous haemorrhage was present in 5 cases at the time of wounding, and in one case it occurred $9 \frac{1}{2}$ months after an operation for retinal detachment. A moderate vitreous haemorrhage was evident in 7 cases. The contracture of organized bands of fibrous tissues was a factor in producing the detachment in 9 cases. Fig. 3

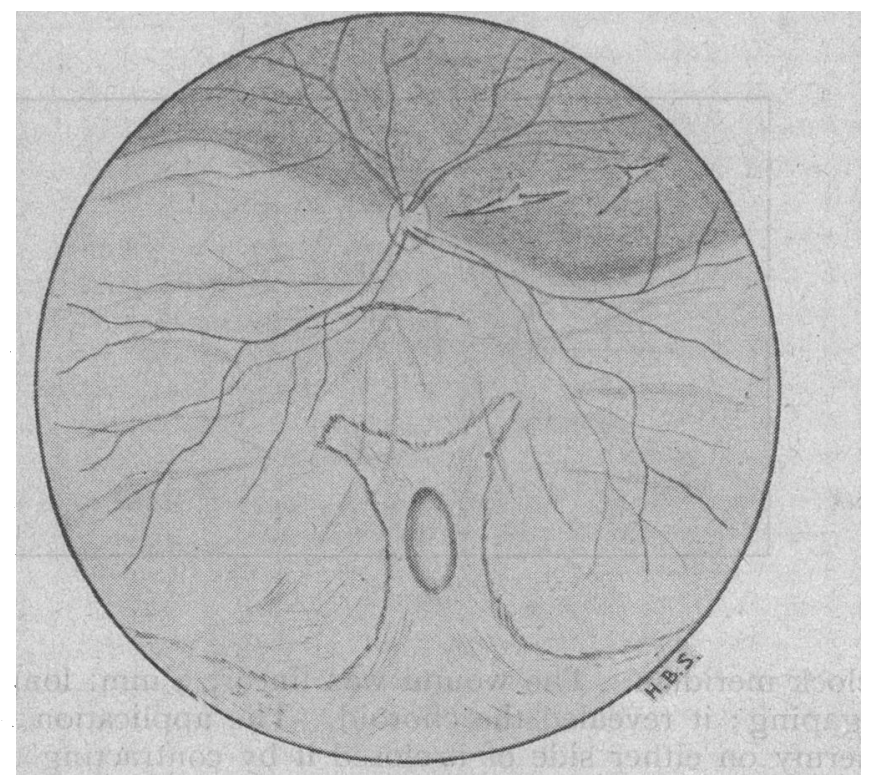

FIG. 3. 
shows, like Fig. 1 the result of contracture of fibrous tissue bands in a contused eye. It is the fundus of the right and only eye of a German prisoner. He was wounded in the face with multiple shell fragments. The retina became detached 14 months after he was wounded. Operative treatment was successful in this case. A line of diathermy applications was made on the sclera beyond the limits of the scarred area, the inter-retinal fluid was drained, and the detached retina pinned down to the choroid. The retina remained in place.

Intra-ocular pressure. In 6 cases of severe contusion of the eye the intra-ocular pressure was reduced. In two of these with total detachment of the retina the intra-ocular pressure was less than $6 \mathrm{~mm} . \mathrm{Hg}$ in one case and $6.5 \mathrm{~mm} . \mathrm{Hg}$ in the other. In one case of severe contusion with retinal detachment on the temporal side the intra-ocular pressure was less than $6 \mathrm{~mm} . \mathrm{Hg}$. In the 4 other cases it was from 1.25 to $9.5 \mathrm{~mm}$.Hg lower than that in the normal other eye. In two cases the intra-ocular pressure was higher in the eye with the retinal detachment than in the other (normal) eye. This amounted to $1.25 \mathrm{~mm} . \mathrm{Hg}$ in one case and $4 \mathrm{~mm} . \mathrm{Hg}$ in the other. After operation the recovery of intra-ocular pressure was slower than in the other groups of retinal detachment. The normal was not reached until 10 to 11 months after operation, and in some instances the intra-ocular pressure remained 1.5 to $3 \mathrm{~mm} . \mathrm{Hg}$ below this.

\section{Results of operation}

Seventeen out of 20 cases in this group were operated on. In 11 the retina was completely replaced. Of the 6 failures, 3 were at first successful but later showed a recurrence localized to part of a quadrant of the fundus, the onset of this after operation being 6 weeks in one case, 5 months in another, and 8 months in the third case. The patient whose retinal detachment recurred 5 months after operation had for military reasons to be evacuated 18 days after operation, and the long journey from Egypt round the Cape of Good Hope to the United Kingdom may have been a factor in causing this misfortune. A spontaneous vitreous haemorrhage 8 months after operation was probably responsible for another case. In one case it was difficult to account for a shallow residual detachment in the lower part of the eye. This patient had an intraocular foreign body extracted by the giant electro-magnet and the detachment treated by diathermy. No definite hole was found in the retina, and despite the recurrence of the detachment his vision was $6 / 9$ and the intra-ocular pressure within physiological limits. In another case a shallow detachment persisted in the lower part of the eye up to two months after operation, when the patient was last seen. Vitreous bands were probably the cause. In the sixth case the operation failed to seal off a large rent at the ora serrata 
which occupied most of the lower temporal quadrant and to secure replacement of over half of the retina. A further operation is necessary in this case.

\section{Vision: Visual field : Refraction}

Vision improved after operation in 7 cases. In one cáse vision was $6 / 18$ before operation and improved to $6 / 9$ (partly) after operation. In another it was $6 / 36$ before operation and was reduced to counting fingers at 1 foot as a result of a late vitreous haemorrhage $9 \frac{1}{2}$ months after operation. In the remaining cases the vision was made neither better nor worse by operation, whether this was successful or not.

In 7 cases the visual field was improved. In one case in which there was a vitreous haemorrhage $9 \frac{1}{2}$ months after operation it became $10^{\circ}$ worse than it was before operation, and in the others there was no appreciable change. In 16 cases in this group the intra-ocular changes as a result of severe trauma made it impossible to estimate the refraction with any measure of accuracy before operation. In one case astigmatism amounting to +1.25 axis $15^{\circ}$ was evident after operation ; but there was a posterior cortical traumatic cataract in this case, so it is difficult to be sure whether the altered refraction was the result of operation or not. In this instance the operation of pinning back a curtain-like detachment in the upper and lower half of the fundus (see Fig. 1) was successful, and the visual result was $6 / 9$, with an unavoidable sacrifice of $30^{\circ}$ in the temporal field. In another case the axis of the astigmatism changed from - $1.25 \mathrm{cyl}$. ax. $90^{\circ}$ before operation' to $-1.5 \mathrm{cyl}$. ax. $45^{\circ}$ after operation.

Comparative results of operative treatment

TABLE C

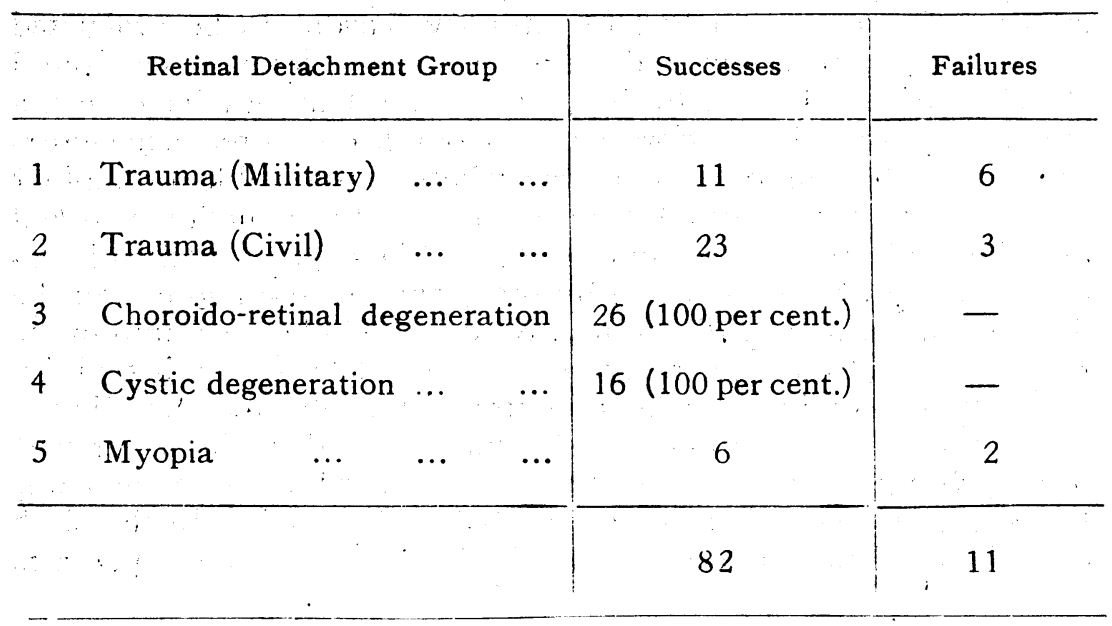


I have counted as a failure any recurrence of retinal detachment however limited and slight, as indeed this was in 6 cases.

Of the 17 cases operated on in the B.L.A. there were 16 successes and 1 failure. The failure occurred in a middle-aged YugoSlav officer, a repatriated prisoner of war in whom three quadrants of the retina had been detached in a myopic eye for 4 years. There was a large ragged rent affecting the upper and lower temporal quadrant. Operation sealed the rent securely and the visual field became nearly full but a shallow detachment recurred 6 weeks after the operation near the ora serrata below. Further operative treatment may have to be considered later if this persists and increases.

The 76 operated on in the M.E.F. showed 86.8 per cent. successes and $13 \cdot 2$ per cent. failures.

It will be seen from Table C. that the results of operative treatment in the military trauma cases compare ill with the other types. of detachment. An explanation of this is, I think, the gross intraocular damage caused to eyes by the severe contusion effects from war missiles traversing the orbit or parts of the cranium and face near the orbit. The intrá-ocular pressure is considerably reduced compared with other types of retinal detachment. In severe cases no measure could be obtained with a Schiötz tonometer (it was less than the lowest reading of $6 \mathrm{~mm} . \mathrm{Hg}$ ) and in others less severe it remained for some months as low as $6-8 \mathrm{~mm} . \mathrm{Hg}$.

Other factors such as organizing vitreous haemorrhage and sheets of blood on the retina and between it and the choroid have already been mentioned.

\section{Surnmary}

The incidence of retinal detachment due to trauma from military missiles is rare. Twenty cases have been analysed. Eighteen of these occurred in the Western desert campaign 1941-43 and 2 in the invasion of Normandy, Belgium and Germany in 1944-45.

The results of treatment compare ill with other types of retinal detachment occurring in a field force.

One case was considered too hopeless to benefit by operation ; 2 others underwent spontaneous recovery; and of the 17 which were operated on 11 were successes and 6 were failures. Pathological reasons for failure are discussed.

I express my thanks to all those ophthalmic colleagues in the Army, serving in the M.E.F. and the B.L.A. who were good enough to send these interesting cases to me and to Brigadier C. W. Graham, Brigadier the Honble. G. Bridgeman, M.C. and Brigadier G. I. Scott, consultants in Ophthalmology in the M.E.F. 1940-43 and to Lt.-Colonel A. Lister, R.A.M.C.' Adviser in Ophthalmology, B.L.A., for their interest and advice from time to time. 